01,07

\title{
Особенности деформирования и разрушения пористого железа при субмикросекундном нагружении
}

\author{
(C) С.А. Атрошенко ${ }^{1,3}$, Г.Г. Савенков ${ }^{2,4}$ \\ ${ }^{1}$ Институт проблем машиноведения РАН, \\ Санкт-Петербург, Россия \\ ${ }^{2}$ Санкт-Петербургский государственный технологический институт (технический университет), \\ Санкт-Петербург, Россия \\ ${ }^{3}$ Санкт-Петербургский государственный университет, \\ Санкт-Петербург, Россия \\ ${ }^{4}$ Физико-технический институт им. А.Ф. Иофффе РАН, \\ Санкт-Петербург, Россия \\ E-mail: satroshe@mail.ru
}

Поступила в Редакцию 3 марта 2021 г.

В окончательной редакции 3 марта 2021 г.

Принята к публикации 14 марта 2021 г.

Посвящена изучению особенностей динамического деформирования и разрушения пористого железа при воздействии кумулятивного „ножа“. Показано, что сверхбыстрое воздействие на преграду привело к интенсивному структурообразованию пористого железа на мезоуровне.

Ключевые слова: структура, сверхбыстрое воздействие, мартенсит, дендриты.

DOI: 10.21883/FTT.2021.07.51033.049

\section{1. Введение}

Высокопористые материалы довольно давно находят применение в различных отраслях промышленности $[1,2]$. В последние годы интерес к ним усилился, что связано, в том числе и с развитием самораспространяющегося высокотемпературного синтеза (СВС-метода) их изготовления $[3,4]$. Преимуществом пористых металлических материалов по сравнению с пористыми керамическими материалами, является их высокая способность поглощать энергию и повышенная пластичность, что позволяет подвергать их высокоскоростному ударному воздействию, в том числе при резком изменении температуры. Поэтому из них, например, изготавливаются эффективные устройства для локализации взрывных и ударных нагрузок [5].

Возрастающее применение пористых металлических материалов вызывает необходимость адекватного расчета динамически нагружаемых конструкций из этих материалов, а следовательно, и адекватного моделирования и анализа физических процессов, происходящих в пористой среде при быстром и сверхбыстром нагружении. Однако вследствие сложности процессов отклика пористой среды на ударно-волновое воздействие выбор и разработка физико-математических моделей поведения пористых материалов при таком воздействии вызывает определенные трудности. Даже, если выбрана некая модель и подобраны эмпирические макрохарактеристики пористой среды, которые позволяют достаточно точно описать поведение конструкции при определенном воздействии, то это не гарантирует адекватного прогнози- рования поведения конструкции при других параметрах нагружения.

При этом необходимо отметить, что физические процессы, происходящие в толще материалов образцов при высокоскоростном воздействии, достаточно слабо поддаются приборному изучению. Имеющиеся результаты импульсного рентгенографирования процессов малоинформативны с точки зрения получения данных о физических явлениях в образцах. Результаты же металлографических исследований образцов после внешнего воздействия требуют тщательного анализа, поскольку являются постфакторными наблюдениями. Тем не менее, металлографические исследования дают на сегодняшний день наиболее достоверные данные о физике процессов при динамическом нагружении материалов [6,7].

Однако следует отметить, что на сегодняшний день преобладающее большинство металлографических исследований материалов производится после их нагружения в диапазоне скоростей деформации $\dot{\varepsilon}=10^{3}-10^{6} \mathrm{~s}^{-1}$. Нагружение материалов при больших скоростях деформации связано с техническими трудностями получения таких скоростей. Как правило, нагружение при скоростях деформации $\dot{\varepsilon}=10^{7}-10^{9} \mathrm{~s}^{-1}$ осуществляется при помощи легкогазовых, электрических и электромагнитных ускорителей, а также при помощи различных источников излучения: лазерных, электронных и ионных пучков и др. [8-10]. И поскольку такие экспериментальные установки, дорогостоящие сами по себе, требуют определенного, зачастую уникального, аппаратурного оснащения и высокой квалификации обслуживающего персонала, то исследования материалов на таких уста- 

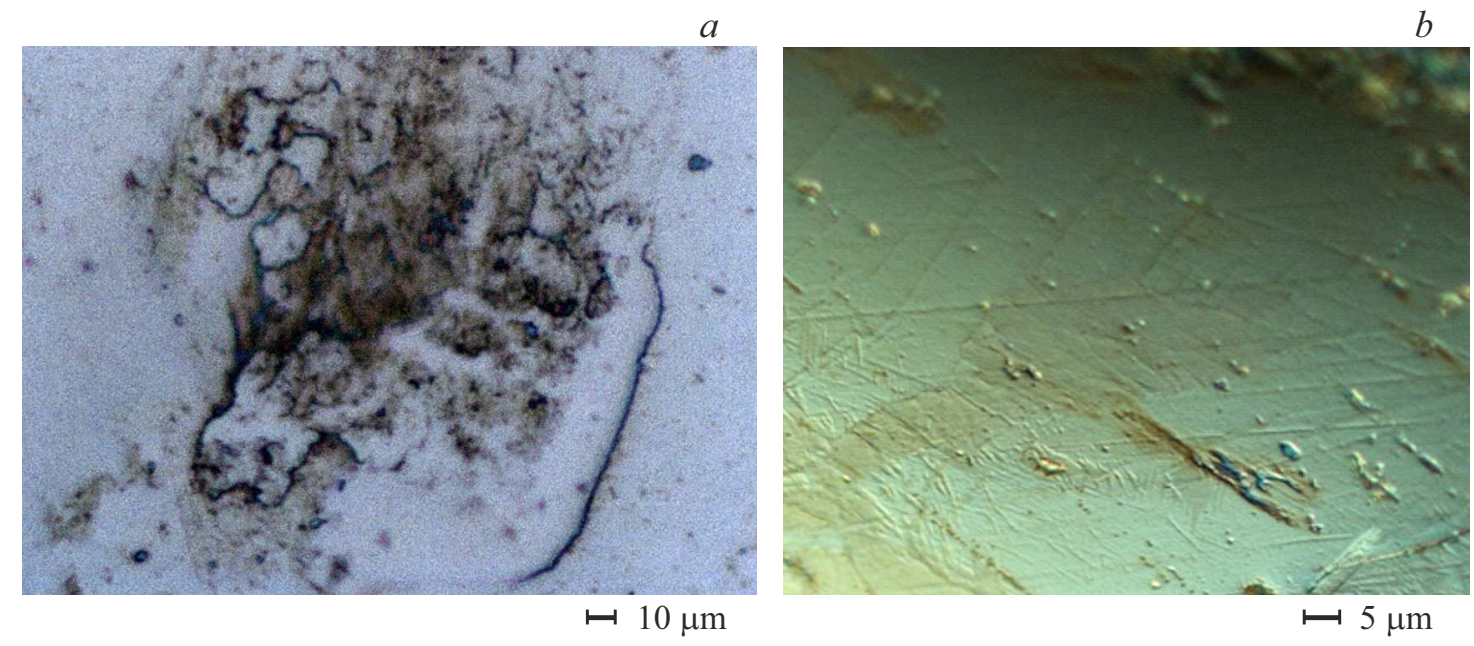

Рис. 1. Исходная микроструктура пористого железа $(a-\times 1600, b-\times 1000$ C_DIC).

новках носят единичный характер. В то же время, как показывают исследования материалов, проводимые при быстром и сверхбыстром нагружении $\left(t \sim 10^{-7}-10^{-9} \mathrm{~s}\right)$, существует принципиальное различие в поведении материалов при таком нагружении от нагружения при меньших длительностях.

Целью настоящей работы было изучение микроструктурных особенностей процесса динамического деформирования и разрушения пористого железа при субмикросекундном нагружении относительно простым и экономичным устройством.

\section{2. Материал, методики экспериментов и обоснование длительности нагружения}

\section{1. Исследуемый материал}

Проводилось изучение образцов в виде частей полуцилиндра из пористого железа марки ПА-Ж ГОСТ 26802-86 толщиной $H=4.0 \mathrm{~mm}$. Образцы испытали воздействие кумулятивного „ножа“ (КН), сформировавшегося при детонации удлиненного кумулятивного заряда (УКЗ) марки 2ТСн-3 [11,12]. Воздействие КН приводило к разделению полуцилиндра на две части.

Исходная структура исследуемого пористого железа представляла собой довольно крупные разноосные зерна феррита размером $(20-50) \mu \mathrm{m} \times(140-170) \mu \mathrm{m}$, встречались также и равноосные зерна диаметром $150-170 \mu \mathrm{m}$, также присутствовали области динамической рекристаллизации (рис. 1, $a$ ), где зерно уменьшается до размера от 0.5 до $1.5 \mu \mathrm{m}$. Кроме того, в структуре присутствовали двойники разного размера и ориентации (рис. $1, b)$, в том числе и пересекающиеся. Размер пор находился в диапазоне $2-15 \mu \mathrm{m}$.

Из разделенных частей полуцилиндра изготавливали шлифы и проводили их металлографический анализ.
Кроме исследования микроструктуры проводили и фрактографический анализ разрушенной поверхности полуцилиндра, при этом определялась по ASTME 436-03 доля вязкой составляющей. Исследования структуры проводились на оптическом микроскопе Axio-Observer Z1 М в светлом поле и в контрасте C-DIC. Исследования поверхности разрушения проводилось на том же микроскопе в темном поле при увеличении 100.

\section{2. Обоснование длительности нагружения}

Кумулятивный „нож“, применявшийся для воздействия на образцы, представляет собой совокупность плоских кумулятивных струй [13], скорость головных частей которых (для нашего случая) составляет $V_{0} \approx 2.8 \mathrm{~km} / \mathrm{s}$, а скорость замыкающих частей $V_{t} \approx 1.4 \mathrm{~km} / \mathrm{s}$. УКЗ устанавливался на внутреннею боковую поверхность полуцилиндра на оптимальное фокусное расстояние $3 \mathrm{~mm}$, таким образом длина (высота) плоской струи была $l_{j}=3 \mathrm{~mm}$. В результате внедрения кумулятивного ножа, как было сказано выше, происходило разделение полуцилиндра на две части.

Средняя скорость плоской струи оценивалась по соотношению [14]:

$$
\langle V\rangle=V_{0} \sqrt{\frac{1+V_{t} / V_{0}+\left(V_{t} / V_{0}\right)^{2}}{3}} .
$$

Расчет по соотношению (1) дает значение средней скорости струи $\langle V\rangle=2.14 \mathrm{~km} / \mathrm{s}$. Как сказано выше, толщина разделенного образца (преграды) - $4.0 \mathrm{~mm}$. Даже, если предположить, что движение плоской кумулятивной струи в пористой среде эквивалентно движению некоторого тела (моделирующего струю) в жидкости (как это сделано в работе [15]), то толщина разделяемой преграды в рамках гидродинамической теории проникания должна быть равна, согласно классической формуле 


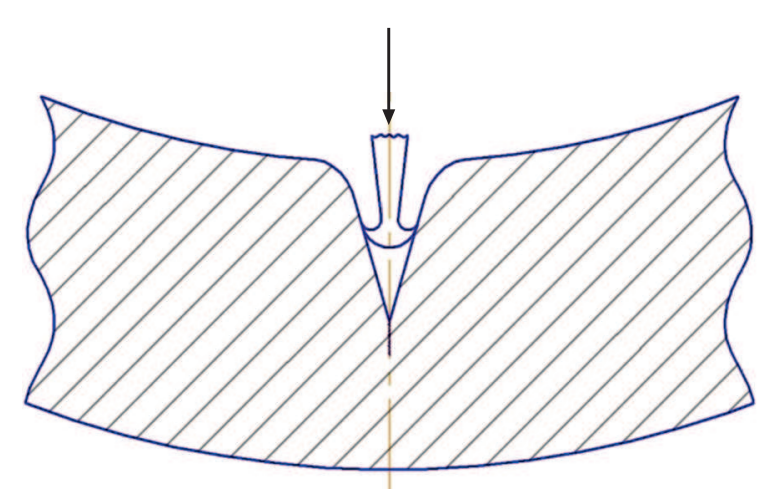

Рис. 2. Схема движения кумулятивного ножа.

Лаврентьева $[13,14]$ :

$$
H=l_{j} \sqrt{\rho_{j} / \rho_{t}},
$$

(здесь $\rho_{j}, \rho_{t}-$ плотности материалов струи и преграды соответственно) $H=3.2 \mathrm{~mm}$. Но соотношение (2) верно для глубины внедрения струи в преграду полубесконечной толщины, в нашем случае толщина преграды имеет конечное значение, поэтому толщина разделяемой преграды должна оцениваться по соотношению [16]:

$$
H=H_{p}+H_{s}
$$

где $H_{p}$ - глубина проникания струи; $H_{s}$ - толщина откольной части преграды. Однако осмотр тыльной части преграды не выявил характерных признаков откола.

Другой причиной столь высокого значения толщины разделенной преграды (образца) может являться то, что кумулятивный „нож“ (КН), по сути, является клиновидным ударником. И тогда, в процессе его внедрения в достаточно хрупкую преграду впереди клиновидного ударника образуется трещина (рис. 2), скорость которой может быть сопоставима со скоростью проникания само- го ударника, что и приводит к столь высокому значению толщины разделяемой преграды.

Полное время процесса разделения преграды можно оценить $t_{H} \sim 0.5 H /\langle V\rangle<1 \mathrm{mks}$. Такое феноменально низкое значение времени процесса (время непосредственного проникания струи меньше $0.5 \mathrm{mks}$ ) без применения уникальных нагружающих устройств наряду с достаточно высокими значениями параметров нагружения пористой среды и дает возможность выявить микроструктурные изменения, происходящие в материале (пористом железе) в экстремальных условиях.

\section{3. Результаты микроструктурных исследований образцов и их анализ}

Внедрение плоской кумулятивной струи в образец привело к следующим изменениям его структуры.

Во-первых, вблизи ( $0.5 \mathrm{~mm})$ фронтальной поверхности (от начала движения кумулятивной струи) наблюдались участки с дендритной структурой (рис. 3), что указывало на достижение в локальных областях (зернах) образца температуры плавления, при этом скорость распространения температурного фронта должна была

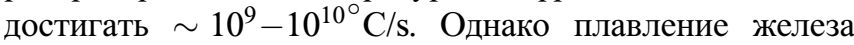
отвечает давлению ударного сжатия $140 \mathrm{GPa}$ [17], а в нашем случае, как показывают самые грубые оценки по соотношениям

$$
p \approx \rho_{0} c_{p} u
$$

либо

$$
p=u \frac{\rho_{1} c_{1}}{\rho_{1} c_{1} / \rho_{0} c_{2}+1},
$$

здесь $\rho_{0}-$ начальная плотность образца, $c_{p}-$ скорость пластической волны в образце, $u=\langle V\rangle$ - массовая скорость в волне напряжения, $\rho_{1}$ - плотность материала ударника, $c_{1,2}$ - скорость звука в материале ударника (кумулятивной струи) и в материале образца соответственно, дают значение давления в диапазоне
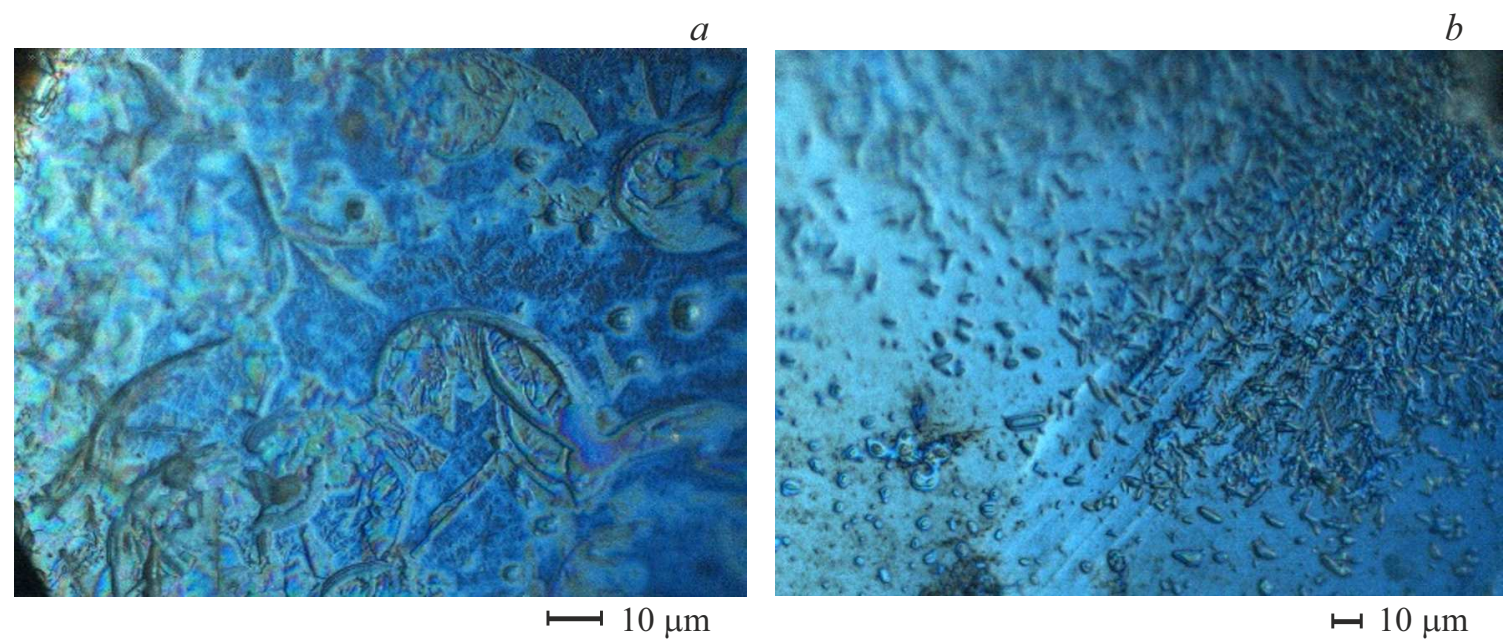

Pис. 3. Дендритная структура пористого железа (×1000) C_DIC. 

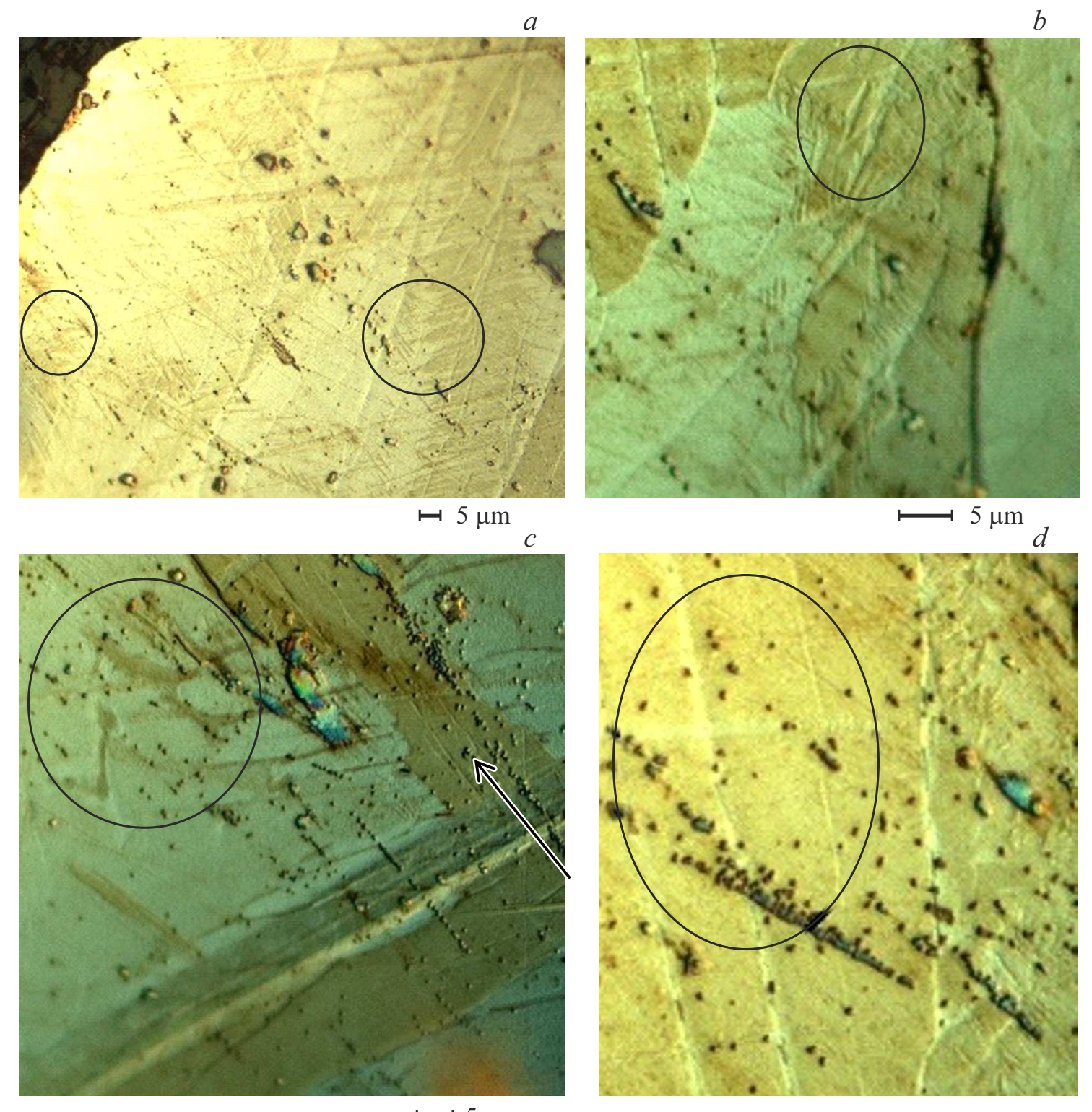

$\longmapsto 5 \mu \mathrm{m}$

Рис. 4. Мартенситные превращения в образце после внедрения кумулятивной струи: $(a-\times 500 ; b, c, d-\times 1000)$ C_DIC (кружками на $a, b, c$ показаны ламели мартенсита; овалом на $d-$ фрагментированная зона, стрелкой на $c-$ ПАС).

60-80 GРа. Поскольку дендритные структуры наблюдались только в отдельных зернах, то можно предполагать, что более высокие добавочные значения давления $(80-60 \mathrm{GPa})$ достигались в них за счет объемного сжатия таких зерен соседними (окружающими) зернами. Кроме того, необходимо учитывать, что фактор сверхбыстрого нагрева приконтактной поверхности образца, связан с неравновесным распределением энергии между структурными элементами твердого тела [18].

Во-вторых, в структуре пористого железа в том же приконтактном слое в некоторых зернах вблизи их границ произошли мартенситные превращения $(\alpha \rightarrow \varepsilon \rightarrow \alpha$ переход), и в них появился игольчатый (линзообраз- ный, фермообразный или двойникованный) мартенсит (рис. $4, a, 4, b$ и $4, c$ соответственно).

Кроме этого, необходимо отметить появление полос адиабатического сдвига (ПАС) (рис. 4,c) и частично фрагментированных структур (рис. $4, d$ ).

По аналогии с работами [19-24] можно полагать, что возникающие мартенситные кристаллы со сверхзвуковой скоростью пронизывают объем зерна, формируя фронты возмущений, часть из которых обгоняет ударную волну, инициировавшую превращение, т.е., по сути, мы имеем некую аналогию с детонационным процессом [24]. В этом случае сверхзвуковая скорость мартенситного превращения является аналогом скорости детонационной волны $D$. В первом приближении 

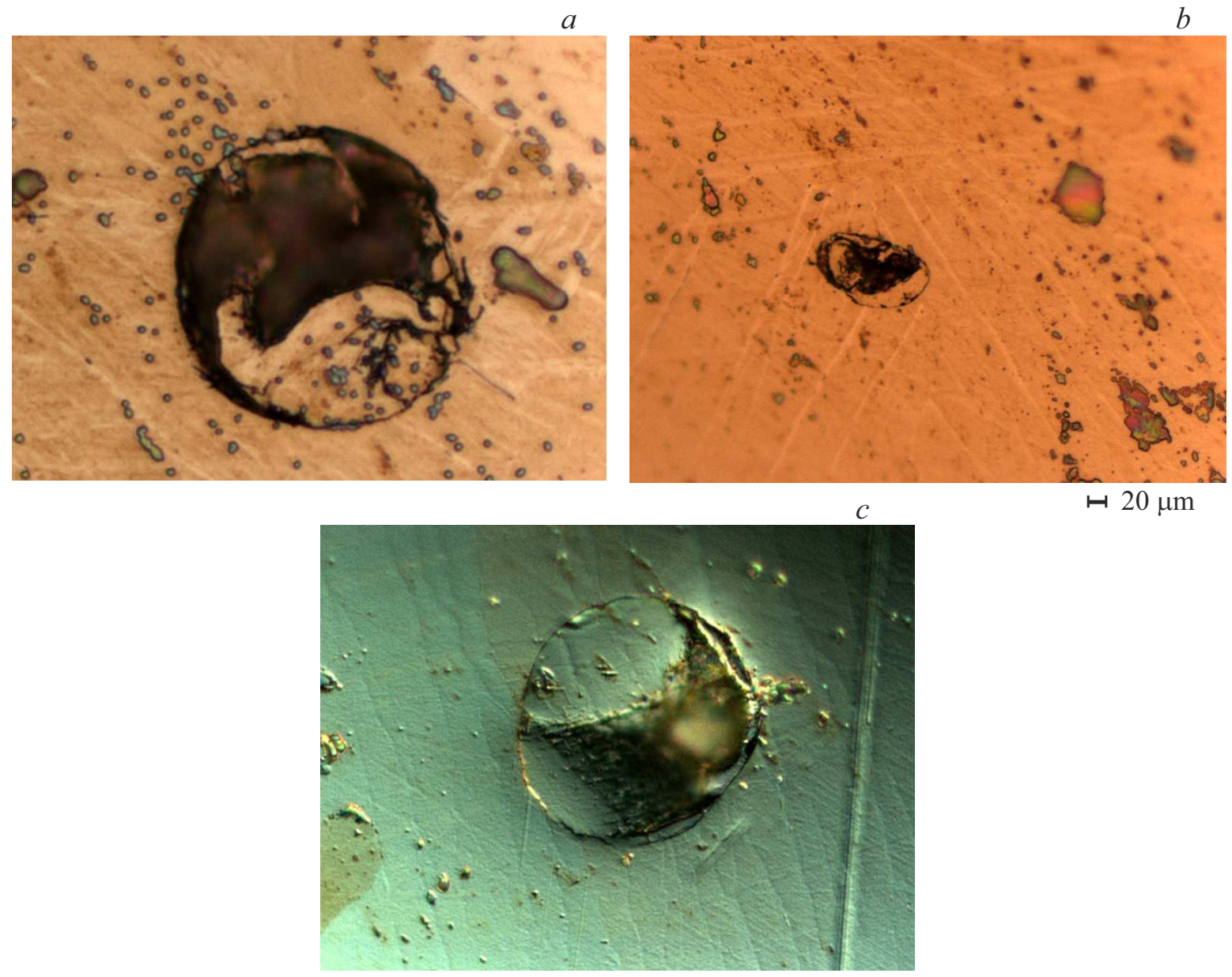

$\mathbf{H} 2 \mu \mathrm{m}$

Рис. 5. Примеры ротационного движения микрообъемов среды: $a-\times 2500, b-\times 1250, c-\times 1600$ C_DIC.

определим эту скорость. Запишем в рамках теории Зельдовича-Неймана-Деринга [25] уравнение сохранения импульса

$$
p=\rho_{j} D U,
$$

где $\rho_{j}-$ плотность феррита; $U-$ массовая скорость движения феррита; $p$ - давление на фронте ударной волны.

Плотность $\alpha$-Fe составляет $7570 \mathrm{~kg} / \mathrm{m}^{3}, \quad$ а $\quad \gamma$-Fe $7750 \mathrm{~kg} / \mathrm{m}^{3}$ [24], примем давление на фронте волны распространения мартенсита в соответствии с вышеприведенной оценкой $p=60-80 \mathrm{GPa}$, а $U=u=2140 \mathrm{~m} / \mathrm{s}$. В результате из (5) получим $3700-4940 \mathrm{~m} / \mathrm{s}$, что вполне сопоставимо со скоростью детонации инициирующих взрывчатых веществ [25].

В-третьих, деформирование материала преграды сопровождалось ротационными движениями микроструктурных объемов среды, о чем свидетельствуют круговые (почти замкнутые) трещины (рис. 5). Кроме круговых присутствовали отдельные трещины, ориентированные под углом $\sim 45^{\circ}$ к поверхности разрушения (рис. 6 ).

Аналогичные трещины при проникании кумулятивного ножа наблюдались и в титановых сплавах [26].
Их образование связано с расклинивающим эффектом, а ориентация со сложным напряженным состоянием в зоне, где распространяется трещина.

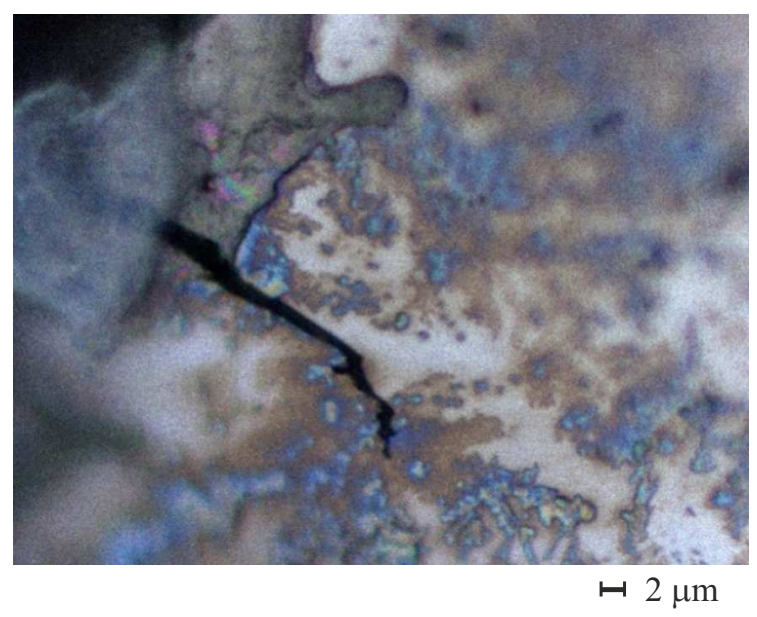

Рис. 6. Трещинообразование в зоне движения кумулятивной струи $(\times 2500)$. 


\section{4. Заключение}

Таким образом, сверхбыстрое воздействие кумулятивной струи на преграду из пористого железа привело к интенсивному структурообразованию мезомасштабного уровня в приповерхностном слое образца.

В принципе, полученные результаты не противоречат волновой теории мартенситного превращения и указывают на то, что процессы динамического деформирования в условиях сверхбыстрого нагружения протекают в условиях сильной неравновесности, приводящей к перераспределению энергии и плавлению отдельных структурных элементов, и гетерогенизации структуры.

\section{Финансирование работы}

Работа выполнена при финансовой поддержке гранта РНФ 17-11-01053.

\section{Конфликт интересов}

Авторы заявляют, что у них нет конфликта интереосв.

\section{Список литературы}

[1] С.Б. Белов. Пористые металлы в машиностроении. Машиностроение, М. (1976). 183 с.

[2] П.А. Витязь. Пористые порошковые материалы и изделия из них. Вышэйш. шк., Минск (1987). 161 с.

[3] Пористые порошковые материалы с анизотропной структурой: методы получения / Под ред. П.А. Витязя. Тонпик, Минск (2005). 236 с.

[4] Д.И. Андриянов, А.П. Амосов, А.Р. Самборук. Вестн. Самарского гос. техн. ун-та. Сер. Техн. науки 43, 3, 73 (2014).

[5] Л.А. Мержиевский, А.В. Тягельский. ФГВ 30, 4, 124 (1994).

[6] С.А. Атрошенко, А.Н. Зубарева, В.А. Морозов, Г.Г. Савенков, А.В. Уткин. ФТТ 60, 2, 234 (2018).

[7] С.А. Атрошенко, А.Ю. Григорьев, Г.Г. Савенков. ФТТ 62 , 11, 1755 (2020).

[8] Методы исследования свойств материалов при интенсивных динамических нагрузках / Под ред. М.В. Жерноклетова. ФГУП РФЯЦ - ВНИИЭФ, Саров (2003). 403 с.

[9] В.А. Морозов. Динамика высокоскоростного нагружения материалов. СПбГУ, СПб (2003). 112 с.

[10] Н.В. Вовненко, Б.А. Зимин, Ю.В. Судьенков. ЖТФ 80, 7 , 41 (2010).

[11] В.И. Колпаков, Г.Г. Савенков, А.С. Мазур, К.А. Рудомёткин. ЖТФ 85, 1, 3 (2015).

[12] С.А. Новиков. Полезные взрывы. РФЯЦ-ВНИИЭФ, Саров (2000). 293 c.

[13] Физика взрыва / Под ред. Л.П. Орленко. Физматлит, М. (2002). T. 2. $656 \mathrm{c}$

[14] Физика взрыва / Под ред. К.П. Станюковича. Наука, М. (1975). $704 \mathrm{c}$.

[15] Ю.А. Тришин. ФГВ 35, 6, 119 (1999).
[16] В.Л. Копнов, Г.Г. Савенков. В сб.: Актуальные вопросы проектирования космических систем и комплексов. Сб. науч. тр. НПО им. С.А. Лавочкина. Блок-ИнформЭкспресс, М. (2005). Вып. 6. С. 200.

[17] А.И. Фунтиков. Теплофизика высоких температур 41, 6, 954 (2003).

[18] Н.В. Вовненко, Б.А. Зимин, Ю.В. Судьенков. ЖТФ 80, 7 , $41(2010)$.

[19] Ю.И. Мещеряков, М.П. Кащенко, В.Б. Васильков, С.А. Атрошенко. Письма в ЖТФ 19, 2, 75 (1993).

[20] С.А. Атрошенко, Ю.И. Мещеряков. ФММ 84, 3, 101 (1997)

[21] S.A. Atroshenko. Mater. Sci. Eng. A 378, 293 (2004).

[22] М.П. Кащенко. Волновая модель роста мартенсита при $\gamma-\alpha$ превращении в сплавах на основе железа. НИЦ „Регулярная и хаотическая динамика“, М.; Ижевский институт компьютерных исследований, Ижевск (2010), $280 \mathrm{c}$.

[23] М.П. Кащенко, В.Г. Чащина. Успехи физ. наук 181, 4, 345 (2011).

[24] M.I. Alymov, V.S. Trofimov, E.V. Petrov. Lett. Mater. 7, 1, 26 (2017).

[25] Физика взрыва / Под ред. Л.П. Орленко. Физматлит, М. (2002). T. 1.832 c.

[26] Г.Г. Савенков. Механизмы деформации и разрушения пластичных и твердых тел при высокоскоростном взаимодействии. Докт. дис. ИПМаш РАН, СПб. (2003). 393 с.

Редактор Д.В. Жуманов 